\title{
The Relationship between Phenolics and Flavonoids Production with Total Non Structural Carbohydrate and Photosynthetic Rate in Labisia pumila Benth. under High $\mathrm{CO}_{2}$ and Nitrogen Fertilization
}

\author{
Mohd Hafiz Ibrahim ${ }^{1}$, Hawa Z.E. Jaafar ${ }^{1, *}$, Asmah Rahmat ${ }^{2}$ and Zaharah Abdul Rahman ${ }^{3}$
}

1 Department of Crop Science, Faculty of Agriculture, University Putra Malaysia, 43400 Serdang, Selangor, Malaysia; E-Mail: mhafizphd@gmail.com (M.H.I.)

2 Department of Nutrition \& Dietetics, Faculty of Medicine \& Health Sciences, University Putra Malaysia, 43400 Serdang, Selangor, Malaysia; E-Mail: asmah@medic.upm.edu.my

3 Department of Land Management, Faculty of Agriculture, University Putra Malaysia, 43400 Serdang, Selangor, Malaysia; E-Mail: zaharah@agri.upm.edu.my

* Author to whom correspondence should be addressed; E-Mail: hawazej@gmail.com or hawazej@agri.upm.edu.my; Tel.: +6-03-8946-6922 / +6-012-372-3585; Fax: +6-03-8943-5973.

Received: 24 November 2010; in revised form: 15 December 2010 / Accepted: 21 December 2010 / Published: 29 December 2010

\begin{abstract}
A factorial split plot $4 \times 3$ experiment was designed to examine and characterize the relationship among production of secondary metabolites (total phenolics, TP; total flavonoids, TF), carbohydrate content and photosynthesis of three varieties of the Malaysian medicinal herb Labisia pumila Benth. namely the varieties alata, pumila and lanceolata under $\mathrm{CO}_{2}$ enrichment $\left(1,200 \mu \mathrm{mol} \mathrm{mol}{ }^{-1}\right)$ combined with four levels of nitrogen fertilization $\left(0,90,180\right.$ and $\left.270 \mathrm{~kg} \mathrm{~N} \mathrm{ha}^{-1}\right)$. No varietal differences were observed, however, as the levels of nitrogen increased from 0 to $270 \mathrm{~kg} \mathrm{~N} \mathrm{ha}^{-1}$, the production of TP and TF decreased in the order leaves $>$ roots $>$ stems. The production of TP and TF was related to increased total non structural carbohydrate (TNC), where the increase in starch content was larger than that in sugar concentration. Nevertheless, the regression analysis exhibited a higher influence of soluble sugar concentration $\left(r^{2}=0.88\right)$ than starch on TP and TF biosynthesis. Photosynthesis, on the other hand, displayed a significant negative relationship with TP and TF production $\left(r^{2}=-0.87\right)$. A decrease in photosynthetic rate with increasing secondary metabolites might be due to an increase in the shikimic acid pathway that results in enhanced production of TP and TF. Chlorophyll content exhibited very
\end{abstract}


significant negative relationships with total soluble sugar, starch and total non structural carbohydrate.

Keywords: $\mathrm{CO}_{2}$ enrichment; total phenolics and flavonoids; carbon:nitrogen ratio; photosynthesis nitrogen use efficiency; total soluble sugar and starch profiling; Kacip Fatimah; medicinal herb

\section{Introduction}

Labisia pumila Benth., popularly known as Kacip Fatimah, is a sub-herbaceous plant with creeping stems from the family Myrsinaceae that is found widespread in Indochina and throughout the Malaysian forest [1]. Traditionally L. pumila has been used by Malay women to induce and facilitate childbirth as well as a post-partum medicine [2]. Stone [3] had categorized three varieties of this herb in Malaysia, namely L. pumila var. alata, L. pumila var. pumila and L. pumila var. lanceolata. Each of the varieties has a different usage. The varieties most universally utilized by the traditional healers are the first two, L. pumila var. alata and L. pumila var pumila. The other uses of this herb are treatment for dysentery, dysmenorrheal, flatulence, and gonorrhea treatments [4].

Recently, it was found that the bioactive compounds of L. pumila consisted of resorcinols, flavonoids and phenolic acid [1,5]. These compounds have been identified as natural antioxidants that may reduce oxidative damage to the human body [6]. The concentration of plant secondary metabolites was found to be influenced by environmental conditions such as light intensity, carbon dioxide levels, temperature, fertilization, biotic and abiotic factors, which can change the concentration of these active constituents [1,7]. Lately, it was found that the enrichment of L. pumila with high levels of $\mathrm{CO}_{2}$ increased the secondary metabolite production (phenolics and flavonoids) of this plant [8]. A similar result was also observed in ginger (Gingiber officianale) [9].

The increase in atmospheric $\mathrm{CO}_{2}$ due to climate change has direct effects on plant secondary metabolites. The effects show a wide range of patterns, either in the amounts of primary and secondary metabolites. Plants produce a wide range of carbon-based secondary metabolites (CBSM) which have important functions such as wound healing, defense against herbivores, control of the rates of plant decomposition and mediation of interaction between plants and soil biota [10]. Among these CBSM the polyphehols derived from the phenylpropanoid pathways such as soluble phenolics and flavonoids are quantitatively the most important, accounting for about $30 \%$ of the organic carbon cycling in the terrestrial biosphere [11]. Under optimum $\mathrm{CO}_{2}$ concentration conditions combined with nutrient resource limitation, which restrict growths to a greater extent than photosynthesis, plants showed an increase in the $\mathrm{C} / \mathrm{N}$ ratios and excess of non-structural carbohydrates [12]. This excess may be then available for the incorporation in CBSM. The carbon nutrient balance (CNB) hypothesis predicts that the availability of excess carbon at a certain nutrient levels leads to the increased production of CBSM metabolites and their precursors [13]. It was also noted that nitrogen fertilization was found to decrease levels of soluble phenolics and condensed tannins in plant tissues [14].

It has been shown that trees grown under elevated $\mathrm{CO}_{2}$ concentrations tend to increase photosynthesis and decrease nitrogen concentration relative to biomass [15]. The increase in plant 
productivity in response to rising $\mathrm{CO}_{2}$ is largely dictated by photosynthesis, respiration, carbohydrate production and their differential allocation between plant organs and the subsequent incorporation into biomass. For this reason, many studies have investigated the effects of elevated $\mathrm{CO}_{2}$ on plant primary metabolism but relatively few studies have investigated the response of plant $\mathrm{CBSM}$ to increasing $\mathrm{CO}_{2}$ and its interaction with nitrogen availability.

The objective of this study was to examine the effects of different nitrogen levels under $\mathrm{CO}_{2}$ enrichment on photosynthesis rate, photosynthesis-nitrogen use efficiency (PNUE), $\mathrm{C} / \mathrm{N}$ ratio, chlorophyll content, primary (total non structural carbohydrate) and secondary metabolite (flavonoids and phenolics) synthesis in three varieties of L. pumila. The relationships among photosynthesis, carbohydrate, and total phenolics and flavonoids of plants exposed to combined $\mathrm{CO}_{2}$ enrichment and nitrogen levels were also determined.

\section{Results and Discussion}

\subsection{Total Flavonoids and Phenolics Content and Their Profiling}

Nitrogen levels had a significant $(P \leq 0.05)$ impact on the production of total phenolics and flavonoid production (Table 1). As more nitrogen was invested steadily from 0 to $270 \mathrm{~kg} \mathrm{~N} \mathrm{ha}{ }^{-1}$, less total phenolic and flavonoid was produced. Labisia pumila Benth. partitioning more of their secondary metabolites in the leaves, followed by the roots and then stems.

Table 1. Accumulation and partitioning of total flavonoids (TF) and total phenolics (TP) in different plant parts of Labisia pumila Benth. under different combinations of nitrogen levels and $\mathrm{CO}_{2}$ enrichment.

\begin{tabular}{cccc}
\hline Nitrogen levels & Plant parts & TF (mg Rutin/g dry weight) & TP (mg Gallic acid/g dry weight) \\
\hline $\mathrm{A}-180 \mathrm{~kg} \mathrm{~N} \mathrm{ha}^{-1} *$ & Leaf & $0.317 \pm 0.017 \mathrm{c}$ & $0.581 \pm 0.019 \mathrm{~d}$ \\
& Stem & $0.143 \pm 0.017 \mathrm{~d}$ & $0.301 \pm 0.017 \mathrm{~d}$ \\
\multirow{2}{*}{$0 \mathrm{~kg} \mathrm{~N} \mathrm{ha}^{-1}$} & Root & $0.308 \pm 0.015 \mathrm{c}$ & $0.296 \pm 0.013 \mathrm{~d}$ \\
& Leaf & $0.803 \pm \mathrm{r} 0.013 \mathrm{a}$ & $1.410 \pm \mathrm{r} 0.028 \mathrm{a}$ \\
& Stem & $0.678 \pm \mathrm{r} 0.022 \mathrm{a}$ & $1.164 \pm \mathrm{r} 0.029 \mathrm{a}$ \\
$90 \mathrm{~kg} \mathrm{~N} \mathrm{ha}^{-1}$ & Root & $0.788 \pm \mathrm{r} 0.013 \mathrm{a}$ & $1.222 \pm \mathrm{r} 0.039 \mathrm{a}$ \\
& Leaf & $0.515 \pm \mathrm{r} 0.022 \mathrm{~b}$ & $1.180 \pm \mathrm{r} 0.032 \mathrm{~b}$ \\
& Stem & $0.388 \pm \mathrm{r} 0.030 \mathrm{~b}$ & $0.927 \pm \mathrm{r} 0.037 \mathrm{~b}$ \\
$180 \mathrm{~kg} \mathrm{~N} \mathrm{ha}^{-1}$ & Root & $0.498 \pm \mathrm{r} 0.022 \mathrm{~b}$ & $0.983 \pm \mathrm{r} 0.051 \mathrm{~b}$ \\
& Leaf & $0.480 \pm \mathrm{r} 0.013 \mathrm{c}$ & $0.862 \pm \mathrm{r} 0.021 \mathrm{c}$ \\
& Stem & $0.357 \pm \mathrm{r} 0.010 \mathrm{c}$ & $0.610 \pm \mathrm{r} 0.025 \mathrm{c}$ \\
$270 \mathrm{~kg} \mathrm{~N} \mathrm{ha}^{-1}$ & Root & $0.464 \pm \mathrm{r} 0.015 \mathrm{c}$ & $0.666 \pm \mathrm{r} 0.040 \mathrm{c}$ \\
& Leaf & $0.212 \pm \mathrm{r} 0.025 \mathrm{~d}$ & $0.576 \pm \mathrm{r} 0.008 \mathrm{~d}$ \\
& Stem & $0.116 \pm \mathrm{r} 0.023 \mathrm{~d}$ & $0.324 \pm \mathrm{r} 0.011 \mathrm{~d}$ \\
& Root & $0.197 \pm \mathrm{r} 0.026 \mathrm{~d}$ & $0.380 \pm \mathrm{r} 0.028 \mathrm{~d}$ \\
\hline
\end{tabular}

All analyses are mean \pm standard error of mean (SEM), $\mathrm{N}=15$. Means not sharing a common single letter were significantly different at $\mathrm{P} \leq 0.05$. $\mathrm{A}=$ Control at ambient $\mathrm{CO}_{2}$ levels $\left(400 \mu \mathrm{mol}^{-1} \mathrm{~mol}^{-1}\right)$ and standard Nitrogen fertilization rates $\left(180 \mathrm{~kg} \mathrm{~N} \mathrm{ha}^{-1}\right)$.

The enhancement of total flavonoids and phenolics of L. pumila seedling was higher under elevated $\mathrm{CO}_{2}$ compared to ambient; and when combined with nitrogen at $180 \mathrm{~kg} \mathrm{ha}^{-1}$, total flavonoids and phenolics increased by $70 \%$ and $170 \%$, respectively. The enhancement of total plant flavonoids and phenolics usually occurred when plant is deficient in nitrogen [16,17]. This improvement in plant 
secondary metabolites might be due to increased total non structural carbohydrates (TNC), as exhibited by the correlation coefficient $\left(\mathrm{r}^{2}=0.81\right)$ in Table 2 , although a higher correlation coefficient $\left(\mathrm{r}^{2}=0.88\right)$ was displayed by total soluble sugar implying that the accumulation of soluble sugar might be more responsible in the up regulation of plant secondary metabolites production. Amin et al. [18] had proposed that the increase in flavonoids content was due to increase in total soluble sugar as observed in onion the increase of in the former by $7 \%$ as a result of the latter's enhancement by $21 \%$.

Table 2. Correlations among the measured parameters in the experiments.

\begin{tabular}{|c|c|c|c|c|c|c|c|c|c|c|c|c|}
\hline Characteristics & 1 & 2 & 3 & 4 & 5 & 6 & 7 & 8 & 9 & 10 & 11 & 12 \\
\hline 1. Photosynthesis & 1 & & & & & & & & & & & \\
\hline 2. PNUE & 0.04 & 1 & & & & & & & & & & \\
\hline 3. Nitrogen & $0.85^{*}$ & -0.47 & 1 & & & & & & & & & \\
\hline 4. $\mathrm{C}: \mathrm{N}$ ratio & $-0.73 *$ & 0.55 & $-0.91 * *$ & 1 & & & & & & & & \\
\hline 5. Chlorophyll a & $0.77 * *$ & -0.38 & $0.88^{* *}$ & $-0.81 * *$ & 1 & & & & & & & \\
\hline 6. Chlorophyll b & $0.77 * *$ & -0.38 & $0.88^{* *}$ & $-0.81 * *$ & 0.90 & 1 & & & & & & \\
\hline 7. T. Chlorophyll & $0.77 *$ & -0.38 & $0.88^{*}$ & $-0.81^{*}$ & 0.90 & 0.90 & 1 & & & & & \\
\hline 8. TSS & $-0.69^{*}$ & 0.43 & $-0.83^{* *}$ & $0.81 * *$ & $-0.88^{* *}$ & $-0.88^{* *}$ & $-0.88 * *$ & 1 & & & & \\
\hline 9. Starch & -0.48 & 0.26 & $-0.55^{* *}$ & $0.57 * *$ & $-0.72 * *$ & $-0.72^{* *}$ & $-0.72 * *$ & $0.88 *$ & 1 & & & \\
\hline 10. TNC & $-0.58^{*}$ & 0.34 & $-0.69 *$ & $0.69 *$ & $-0.81^{*}$ & $-0.81^{*}$ & $-0.81^{*}$ & $0.96^{* *}$ & $0.98 * *$ & 1 & & \\
\hline 11. Flavonoids & $0.77 * *$ & -0.38 & $0.88 * *$ & $-0.81 *$ & $0.90^{* *}$ & $0.90^{* *}$ & $0.90^{* *}$ & $-0.88^{*}$ & $-0.72 * *$ & $-0.80^{* *}$ & 1 & \\
\hline 12. Phenolics & $0.77 * *$ & $-0.38 *$ & $0.88 * *$ & $-0.81 *$ & $0.90 * *$ & $0.90^{* *}$ & $0.90 * *$ & $-0.88^{*}$ & $-0.72 *$ & $-0.81 *$ & 1.00 & 1 \\
\hline
\end{tabular}

$*$ and $* *$ respectively significant at $P \leq 0.05$ or $P \leq 0.01$.

\subsection{Total Soluble Sugar, Starch and Total Non Structural Carbohydrate (TNC) and Their Profiling}

The accumulation and partitioning of carbohydrates were influenced by the nitrogen levels applied to L. pumila ( $\mathrm{P} \leq 0.05)$. The accumulation of carbohydrates in different parts of the plant followed a descending order of leaf $>$ root $>$ stem. As the nitrogen fertilization increased, the concentration of total soluble sugar, starch and TNC decreased (Table 3). The concentration of sucrose and starch registered the lowest values under $270 \mathrm{~kg} \mathrm{~N} \mathrm{ha}{ }^{-1}$, compared to other nitrogen treatments. Under ambient conditions at a standard fertilization rate of $180 \mathrm{~kg} \mathrm{~N} \mathrm{ha}^{-1}$ less sucrose and starch were produced in the leaf, stem and root compared to those plants exposed to high $\mathrm{CO}_{2}$ concentration with the same fertilization level. In all plant parts of L. pumila, the increase in starch content was larger than the increase in sugar concentration [19]. Results thus suggested that the $\mathrm{N}$-fertilization of plant under high $\mathrm{CO}_{2}$ was able to enhance the soluble sugar and starch contents, which had simultaneously enhanced the TNC. Similar observation was found by other researchers [20-23]. The accumulation of carbohydrate in low nitrogen-fertilized plant might be due to the reduction in sink size of the plant when nitrogen is limited; hence, reducing the translocation of carbohydrates to other plant parts [24]. When sink strength was reduced under low nitrogen fertilization, the extra carbohydrates accumulated in L. pumila plants might be channeled for the production of secondary metabolites (total phenols and flavonoids), thus explaining the reason why the production of secondary metabolites was up-regulated 
in low nitrogen fertilization. It is possible that when photosynthetic performance is suppressed under insufficient nitrogen supply, recycling of the enzymatic nitrogen required for secondary metabolism may occur resulting in possible increase in secondary metabolites (phenolics and flavonoids) [25].

Table 3. Accumulation and partitioning of total soluble sugar (TSS), starch and total non structural carbohydrate (TNC) in different plant parts of Labisia pumila Benth. under different combinations of nitrogen levels and $\mathrm{CO}_{2}$ enrichment.

\begin{tabular}{ccccc}
\hline Nitrogen levels & Plant parts & $\begin{array}{c}\text { TSS (mg sucrose /g } \\
\text { dry weight) }\end{array}$ & $\begin{array}{c}\text { Starch (mg glucose /g } \\
\text { dry weight) }\end{array}$ & $\begin{array}{c}\text { TNC (mg /g dry } \\
\text { weight) }\end{array}$ \\
\hline A $-180 \mathrm{~kg} \mathrm{~N} \mathrm{ha}^{-1 *}$ & Leaf & $24.06 \pm 0.51 \mathrm{c}$ & $60.11 \pm 0.19 \mathrm{~d}$ & $84.16 \pm 2.32 \mathrm{c}$ \\
& Stem & $16.70 \pm 1.15 \mathrm{~d}$ & $23.01 \pm 0.27 \mathrm{~d}$ & $40.14 \pm 1.67 \mathrm{~d}$ \\
& Root & $20.21 \pm 0.51 \mathrm{c}$ & $49.6 \pm 0.33 \mathrm{~d}$ & $70.21 \pm 2.32 \mathrm{c}$ \\
$0 \mathrm{~kg} \mathrm{~N} \mathrm{ha}^{-1}$ & Leaf & $42.71 \pm 0.50 \mathrm{a}$ & $89.41 \pm 0.28 \mathrm{a}$ & $131.32 \pm 3.21 \mathrm{a}$ \\
& Stem & $32.04 \pm 0.84 \mathrm{a}$ & $80.16 \pm 0.29 \mathrm{a}$ & $113.21 \pm 1.56 \mathrm{a}$ \\
& Root & $38.09 \pm 0.50 \mathrm{a}$ & $78.22 \pm 0.49 \mathrm{a}$ & $117.34 \pm 3.56 \mathrm{a}$ \\
$90 \mathrm{~kg} \mathrm{~N} \mathrm{ha}^{-1}$ & Leaf & $37.45 \pm 0.49 \mathrm{~b}$ & $78.18 \pm 0.62 \mathrm{~b}$ & $116.7 \pm 5.77 \mathrm{~b}$ \\
& Stem & $22.26 \pm 0.44 \mathrm{~b}$ & $45.27 \pm 0.47 \mathrm{~b}$ & $67.23 \pm 6.22 \mathrm{~b}$ \\
& Root & $33.66 \pm 0.49 \mathrm{~b}$ & $67.98 \pm 0.51 \mathrm{~b}$ & $103.21 \pm 7.55 \mathrm{~b}$ \\
$180 \mathrm{~kg} \mathrm{~N} \mathrm{ha}^{-1}$ & Leaf & $32.64 \pm 0.59 \mathrm{c}$ & $86.22 \pm 0.23 \mathrm{c}$ & $118.78 \pm 5.67 \mathrm{~b}$ \\
& Stem & $15.10 \pm 0.99 \mathrm{~d}$ & $51.03 \pm 0.25 \mathrm{c}$ & $66.31 \pm 6.90 \mathrm{c}$ \\
& Root & $28.86 \pm 0.58 \mathrm{c}$ & $66.67 \pm 0.44 \mathrm{c}$ & $96.75 \pm 7.90 \mathrm{c}$ \\
$270 \mathrm{~kg} \mathrm{~N} \mathrm{ha}^{-1}$ & Leaf & $23.80 \pm 1.16 \mathrm{~d}$ & $57.66 \pm 0.23 \mathrm{~d}$ & $82.22 \pm 6.89 \mathrm{~d}$ \\
& Stem & $8.96 \pm 0.70 \mathrm{~d}$ & $32.42 \pm 0.21 \mathrm{~d}$ & $41.31 \pm 8.65 \mathrm{~d}$ \\
& Root & $20.02 \pm 1.17 \mathrm{~d}$ & $48.20 \pm 0.28 \mathrm{~d}$ & $68.31 \pm 7.96 \mathrm{~d}$ \\
\hline
\end{tabular}

All analyses are mean \pm standard error of mean (SEM), $\mathrm{N}=15$. Means not sharing a single letter were significantly different at $\mathrm{P} \leq 0.05$. $\mathrm{A}=\mathrm{Control}$ at ambient $\mathrm{CO}_{2}$ levels $\left(400 \mu \mathrm{mol}^{-1} \mathrm{~mol}^{-1}\right)$ and standard Nitrogen fertilization rates $\left(180 \mathrm{~kg} \mathrm{~N} \mathrm{ha}^{-1}\right)$.

Table 4. Effects of different nitrogen levels on some physiological parameters in L. pumila Benth. under $\mathrm{CO}_{2}$ enrichment.

\begin{tabular}{|c|c|c|c|c|c|}
\hline Parameters & *Ambient-180 kg N h & 0 kg N h $^{-1}$ & $90 \mathrm{~kg} \mathrm{~N} \mathrm{~h}^{-1}$ & $180 \mathrm{~kg} \mathrm{~N} \mathrm{~h}^{-1}$ & $270 \mathrm{~kg} \mathrm{~N} \mathrm{~h}^{-1}$ \\
\hline Photosynthesis & $5.29 \pm 0.04 \mathrm{c}$ & $4.98 \pm 0.25 \mathrm{a}$ & $7.29 \pm 0.26 b$ & $8.46 \pm 0.24 c$ & $11.75 \pm 0.47 \mathrm{~d}$ \\
\hline PNUE $^{1}$ & $1.79 \pm 0.06 \mathrm{c}$ & $3.09 \pm 0.18 \mathrm{a}$ & $3.01 \pm 0.17 b$ & $2.45 \pm 0.12 c$ & $2.66 \pm 0.12 \mathrm{~d}$ \\
\hline Leaf $\mathrm{N}$ content & $2.96 \pm 0.10 \mathrm{c}$ & $1.63 \pm 0.09 \mathrm{a}$ & $2.46 \pm 0.11 \mathrm{~b}$ & $3.47 \pm 0.09 \mathrm{c}$ & $4.42 \pm 0.08 \mathrm{~d}$ \\
\hline $\mathrm{C}: \mathrm{N}^{2}$ & $12.64 \pm 0.65 \mathrm{c}$ & $28.15 \pm 1.15 \mathrm{a}$ & $18.29 \pm 0.72 b$ & $13.12 \pm 0.42 \mathrm{c}$ & $10.29 \pm 0.18 \mathrm{~d}$ \\
\hline Chlorophyll a & $5.48 \pm 0.06 \mathrm{c}$ & $3.60 \pm 0.123 \mathrm{a}$ & $4.35 \pm 0.123 b$ & $5.30 \pm 0.05 \mathrm{c}$ & $6.16 \pm 0.10 \mathrm{~d}$ \\
\hline Chlorophyll b & $16.38 \pm 0.15 c$ & $12.30 \pm 0.26 \mathrm{a}$ & $13.92 \pm 0.26 b$ & $15.96 \pm 0.11 \mathrm{c}$ & $17.85 \pm 0.22 \mathrm{~d}$ \\
\hline Chlorophyll a +b & $21.86 \pm 0.21 \mathrm{c}$ & $15.90 \pm 0.39 a$ & $18.21 \pm 0.38 b$ & $21.26 \pm 0.16 \mathrm{c}$ & $24.01 \pm 0.33 \mathrm{~d}$ \\
\hline Total soluble sugar & $24.04 \pm 0.52 c$ & $42.72 \pm 0.50 \mathrm{a}$ & $37.45 \pm 0.49 b$ & $32.64 \pm 0.60 \mathrm{c}$ & $23.80 \pm 1.17 \mathrm{~d}$ \\
\hline Starch & $58.04 \pm 0.52 c$ & $84.05 \pm 2.11 \mathrm{a}$ & $78.78 \pm 2.18 b$ & $72.75 \pm 2.41 \mathrm{c}$ & $63.91 \pm 2.98 \mathrm{~d}$ \\
\hline $\mathrm{TNC}^{3}$ & $82.07 \pm 1.03 \mathrm{c}$ & $126.77 \pm 2.47 \mathrm{a}$ & $116.24 \pm 2.58 b$ & $105.40 \pm 2.93 c$ & $87.71 \pm 4.10 \mathrm{~d}$ \\
\hline Total flavonoids & $0.31 \pm 0.01 \mathrm{c}$ & $0.51 \pm 0.01 \mathrm{a}$ & $0.47 \pm 0.01 \mathrm{~b}$ & $0.33 \pm 0.01 \mathrm{c}$ & $0.30 \pm 0.01 d$ \\
\hline Total phenolics & $1.16 \pm 0.21 \mathrm{c}$ & $1.43 \pm 0.14 \mathrm{a}$ & $1.35 \pm 0.23 b$ & $1.25 \pm 0.32 \mathrm{c}$ & $0.71 \pm 0.24 \mathrm{~d}$ \\
\hline
\end{tabular}

All analyses are mean \pm standard error of mean (SEM), $\mathrm{N}=15$. Means not sharing single letter were significantly different at $\mathrm{P} \leq 0.05$. ${ }^{*}$ Control at ambient $\mathrm{CO}_{2}$ levels $\left(400 \mu \mathrm{mol}^{-1} \mathrm{~mol}^{-1}\right)$ and standard nitrogen fertilization rate $\left(180 \mathrm{~kg} \mathrm{~N} \mathrm{ha}^{-1}\right) .{ }^{1}=$ Photosynthesis nitrogen use efficiency $\left(\mu \mathrm{mol} \mathrm{mol}{ }^{-1} \mathrm{~N} \mathrm{~s}^{-1}\right) ;{ }^{2}=$ carbon to nitrogen ratio; ${ }^{3}=$ total non structural carbohydrate $\left(\mathrm{mg} \mathrm{g}^{-1}\right)$. 


\subsection{Photosynthesis and Photosynthesis Nitrogen Use Efficiency (PNUE)}

The net assimilation rate (photosynthesis) was influenced by nitrogen levels applied $(P \leq 0.05)$, however, no varietal differences were observed. Leaf photosynthesis rate increased with increasing nitrogen fertilization in an ascending oder $0>90>180>270 \mathrm{~kg} \mathrm{~N} \mathrm{ha}^{-1}$. The highest photosynthesis was obtained in L. pumila exposed to $\mathrm{CO}_{2}$ enrichment combined with $270 \mathrm{~kg} \mathrm{~N}^{-1}\left(11.75 \mu \mathrm{mol} \mathrm{m}^{-2} \mathrm{~s}^{-1}\right)$ compared to without $\mathrm{N}$ fertilization (4.98 $11.75 \mu \mathrm{mol} \mathrm{m}^{-2} \mathrm{~s}^{-1}$; Table 4). However, under ambient $\mathrm{CO}_{2}$, plants recorded $6 \%$ higher photosynthesis $\left(5.29 \mu \mathrm{mol} \mathrm{m} \mathrm{m}^{-2} \mathrm{~s}^{-1}\right)$ when fertilized with $180 \mathrm{~kg} \mathrm{~N} \mathrm{ha}^{-1}$ compared to the plant raised under elevated $\mathrm{CO}_{2}\left(4.98 \mu \mathrm{mol} \mathrm{m}^{-2} \mathrm{~s}^{-1}\right)$ but without $\mathrm{N}$ fertilization $\left(0 \mathrm{~kg} \mathrm{~N} \mathrm{Ha}^{-1}\right)$. The finding showed the importance $\mathrm{N}$ in further enhancing leaf gas exchange of L. pumila plants exposed to $\mathrm{CO}_{2}$ enrichment.

Plants fertilized with less $\mathrm{N}$ levels were inclined to record higher PNUE values. The increase in PNUE signified that the plants were more efficient in utilizing nitrogen due low nitrogen availability [26]. Results of the present study showed that a decrease in photosynthesis could have stimulated the production of plant secondary metabolites, as shown by the negative correlation coefficient (Table 2) between photosynthesis and secondary metabolites $\left(r^{2}=-0.77\right)$ of total phenolics and flavonoids. A possible explanation to this might be that the decrease in photosynthetic rate could have increased the shikimic acid pathway that enhanced the production of plant secondary metabolites, and this is due to increase in the concentration of soluble sugar [27].

\subsection{Leaf Nitrogen and Carbon to Nitrogen Ratio (C:N)}

The enhancement of $\mathrm{N}$ fertilization significantly improved leaf nitrogen content $(P \leq 0.05)$. As nitrogen levels increased from 0 to $270 \mathrm{~kg} \mathrm{~N} \mathrm{ha}^{-1}$ leaf tissue nitrogen also increased considerably. The increase in leaf tissue nitrogen might result from intensification of nitrate content in the leaf that signified the enhanced nitrate assimilation of plant under elevated $\mathrm{CO}_{2}$ [28]. Simultaneously, the increase in leaf nitrogen content had lead to reduction in plant $\mathrm{C}: \mathrm{N}$ ratio under high $\mathrm{N}$ fertilization. High $\mathrm{CO}_{2}$ treatment combined with the highest nitrogen level $\left(270 \mathrm{~kg} \mathrm{~N} \mathrm{ha}^{-1}\right)$ reduced the $\mathrm{C}: \mathrm{N}$ ratio (10.29), whilst when combined with $0 \mathrm{~kg} \mathrm{~N} \mathrm{ha}^{-1}$, had increased the $\mathrm{C}: \mathrm{N}$ ratio (28.15) by $173 \%$. A similar increase in $\mathrm{C}: \mathrm{N}$ ratio of plants enriched with high $\mathrm{CO}_{2}$ under low nitrogen was also observed by Fonseca et al. [23]. High $\mathrm{C}: \mathrm{N}$ ratio had a significant positive relationship $(P \leq 0.01)$ with total flavonoids and phenolics compounds $\left(r^{2}=0.81\right.$; Table 2$)$ signifying a good direct association between the $\mathrm{C}: \mathrm{N}$ ratio and plant secondary metabolites. Conversely, the $\mathrm{C}: \mathrm{N}$ ratio displayed a significant negative relationship with photosynthesis $\left(\mathrm{r}^{2}=-0.71\right)$, implying that increase in C:N ratio decreased the photosynthetic capacity of L. pumila. Winger et al. [29] attributed the increase in C:N ratio that had decreased the photosynthetic capacity to increase in carbohydrate accumulation, which repressed photosynthetic protein production, especially the Rubisco. In the present study, the increase in C:N ratio had also reduced the photosynthetic capacity of $L$. pumila seedlings, and this suggested an enhanced synthesis of plant secondary metabolites, especially the flavonoids and phenolics [30]. 


\subsection{Chlorophyll Content}

Chlorophyll content was influenced by the application of Nitrogen $(P \leq 0.01)$. As the levels of $\mathrm{N}$ fertilization increased from 0 to $270 \mathrm{~kg} \mathrm{~N} \mathrm{ha}^{-1}$, chlorophyll $\mathrm{a}, \mathrm{b}$ and total chlorophyll $\mathrm{a}+\mathrm{b}$ were also enhanced. The increase in chlorophyll content with increasing nitrogen has been reported by Suza and Valio [31]. It was found from the correlation (Table 2) that chlorophyll a, b and total were significantly $(P \leq 0.01)$ and negatively related. Competition between secondary metabolites and chlorophyll content fits well with the prediction of protein competition model (PCM) that the secondary metabolites content is controlled by the competition between protein and secondary metabolites biosynthesis pathway and its metabolites regulation. The negative relationship between the secondary metabolites and chlorophyll is a sign of gradual switch of investment from protein to polyphenols production [32]. The same discovery was also obtained by Michel et al. [33] on flavonoids and chlorophyll content in Arabidopsis, which suggested that the production of secondary metabolites was competing with light harvesting protein when soil nitrogen was low.

\section{Experimental}

\subsection{Experimental Location, Plant Materials and Treatments}

The experiments were carried out under a growth house at Ladang 2, Faculty of Agriculture Glasshouse Complex, Universiti Putra Malaysia (longitude $101^{\circ} 44^{\prime} \mathrm{N}$ and latitude $2^{\circ} 58^{\prime} \mathrm{S}, 68 \mathrm{~m}$ above sea level) with a mean atmospheric pressure of $1.013 \mathrm{kPa}$. Three-month old L. pumila seedlings of var alata, var pumila and var lanceolata were left for a month to acclimatize in a nursery until ready for the treatments. Carbon dioxide enrichment treatment started when the seedlings reached 4 months of age where plants were exposed to $1,200 \mathrm{\mu mol}^{-1} \mathrm{~mol}^{-1} \mathrm{CO}_{2}$ and fertilized with four levels of nitrogen concentrations viz. $0,90,180$ and $270 \mathrm{~kg} \mathrm{~N} \mathrm{Ha}^{-1}$. The fertilization with nitrogen levels were split into three applications. A control at ambient $\mathrm{CO}_{2}\left(400 \mu \mathrm{mol}^{-1} \mathrm{~mol}^{-1}\right)$ with standard $\mathrm{N}$ fertilization (180 $\mathrm{kg} \mathrm{N} \mathrm{ha}^{-1}$ ) was included to compare plant responses to high $\mathrm{CO}_{2}$ combined with different levels of $\mathrm{N}$. This factorial experiment was arranged in a split plot using a randomized complete block design with nitrogen levels being the main plot, and varieties as the sub-plot replicated three times. Each treatment consisted of ten seedlings.

\subsection{Growth House Microclimate and $\mathrm{CO}_{2}$ Enrichment Treatment}

The seedlings were raised in specially constructed growth houses receiving 12-h photoperiod and average photosynthetic photon flux density of $300 \mu \mathrm{mol} \mathrm{m} \mathrm{m}^{-2} \mathrm{~s}^{-1}$. Day and night temperatures were recorded at $30 \pm 1.0^{\circ} \mathrm{C}$ and $20 \pm 1.5{ }^{\circ} \mathrm{C}$, respectively, and relative humidity at about $70 \%$ to $80 \%$. Vapor pressure deficit ranged from 1.01 to $2.52 \mathrm{kPa}$. Carbon dioxide at $99.8 \%$ purity was supplied from a high-pressure $\mathrm{CO}_{2}$ cylinder and injected through a pressure regulator into fully sealed $2 \mathrm{~m} \times 3 \mathrm{~m}$ growth houses at 2-h daily and applied continuous from 08:00 to 10:00 a.m. [34]. The $\mathrm{CO}_{2}$ concentration at different treatments was measured using Air Sense ${ }^{\text {TM }} \mathrm{CO}_{2}$ sensors designated to each chamber during $\mathrm{CO}_{2}$ exposition period. Plants were watered three to four times a day at 5 min per 
session to ensure normal growth of plant using drip irrigation with emitter capacity of $2 \mathrm{~L} \mathrm{hr}^{-1}$. The experiment lasted for 15 weeks from the onset of treatment.

\subsection{Total Phenolics and Total Flavonoid Quantification}

The method of extraction and quantification for total phenolics and flavonoids contents followed after Jaafar et al. [8]. An amount of ground tissue sample $(0.1 \mathrm{~g})$ was extracted with $80 \%$ ethanol $(10 \mathrm{~mL})$ on an orbital shaker for 120 minutes at $50{ }^{\circ} \mathrm{C}$. The mixture was subsequently filtered (Whatman $^{\mathrm{TM}}$ No.1), and the filtrate was used for the quantification of total phenolics and total flavonoids. Folin - Ciocalteu reagent (diluted 10-fold) was used to determine the total phenolics content of the leaf samples. Two hundred $\mu$ of the sample extract was mixed with Follin-Ciocalteau reagent $(1.5 \mathrm{~mL})$ and allowed to stand at $22{ }^{\circ} \mathrm{C}$ for 5 minutes before adding $\mathrm{NaNO}_{3}$ solution $(1.5 \mathrm{~mL}$, $\left.60 \mathrm{~g} \mathrm{~L}^{-1}\right)$. After two hours at $22^{\circ} \mathrm{C}$, absorbance was measured at $725 \mathrm{~nm}$. The results were expressed as $\mathrm{mg} \mathrm{g}^{-1}$ gallic acid equivalent (mg GAE/ $\mathrm{g}$ dry sample). For total flavonoids determination, sample $(1 \mathrm{~mL})$ was mixed with $\mathrm{NaNO}_{3}(0.3 \mathrm{~mL})$ in a test tube covered with aluminium foil, and left for 5 minutes. Then $10 \% \mathrm{AlCl}_{3}(0.3 \mathrm{~mL})$ was added followed by addition of $1 \mathrm{M} \mathrm{NaOH}(2 \mathrm{~mL})$ and the absorbance was measured at $510 \mathrm{~nm}$ using rutin as a standard (mg rutin/ $\mathrm{g}$ dry sample).

\subsection{Starch Determination}

Starch content was determined spectrophometrically using method by Thayumanavam and Sadasivam [35]. In this method, dry sample (about $0.5 \mathrm{~g}$ ) was homogenized in hot $10 \mathrm{ml} 80 \%$ ethanol to remove the sugar. The sample was then centrifuged at 5,000 rpm for 5 minute and then the residue was retained. After that, distilled water $(5.0 \mathrm{~mL})$ and $52 \%$ perchloric acid $(6.5 \mathrm{~mL})$ were added to the residue, then the solution was centrifuged and the supernatant separated and then filtered through no. 5 filter paper (Whatman). The processes were repeated until the supernatant was made up to $100 \mathrm{~mL}$. An aliquot of the supernatant $(100 \mu \mathrm{L})$ was added to distilled water until the volume became $1 \mathrm{~mL}$. After that, $4 \mathrm{ml}$ anthrone reagent (Sigma, USA; prepared with 95\% sulphuric acid by adding $2 \mathrm{~g}$ of anthrone to $100 \mathrm{ml} 95 \%$ sulphuric acid) was added to a tube. The mixed solution was placed in the water bath at $100{ }^{\circ} \mathrm{C}$ for eight minutes and then cooled to the temperature room, and then the sample was read at absorbance of $630 \mathrm{~nm}$ to determine the sample starch content. Glucose was used as a standard and starch content was expressed as mg glucose equivalent /g dry sample.

\subsection{Soluble Carbohydrates}

Soluble carbohydrates were measured spectrophotometrically using the method described by Edward [36]. Samples $(0.5 \mathrm{~g})$ were placed in $15 \mathrm{~mL}$ conical tubes. Then distilled water $(10 \mathrm{~mL})$ was added and the mixture was then vortexed and incubated for 10 minutes. Anthrone reagent was prepared using anthrone $(0.1 \mathrm{~g})$ that was dissolved in $95 \%$ sulphuric acid $(50 \mathrm{~mL})$. Sucrose was used as a standard stock solution to prepare a standard curve for the quantification of sucrose in the sample. The mixed sample of ground dry sample and distilled water was centrifuged at a speed of 3,400 rpm for 10 minutes and then filtered to get the supernatant. To an aliquot ( $4 \mathrm{~mL}$ ) of the sample was added anthrone reagent $(8 \mathrm{~mL})$ and the mixture was placed in a waterbath set at $100{ }^{\circ} \mathrm{C}$ for 5 minutes before 
the sample was measured at absorbance $620 \mathrm{~nm}$ using UV160U spectrophotometer (Shimadzu, Japan). The soluble sugar in the sample was expresses as mg sucrose/ g dry sample.

\subsection{Total Non Structural Carbohydrate (TNC)}

The total non structural carbohydrate was calculated as the sum of total soluble sugar and starch content [24].

\subsection{Chlorophyll Content}

Total chlorophyll content was measured by method from Idso et al. [37] using fresh weight basis. Prior to each destructive harvest each seedling was analyzed for the leaf chlorophyll relative reading (SPAD meter 502, Minolta Inc, USA). The leaves of Labisia pumila with different greenness (yellow, light green and dark green) were selected for analysis and total leaf chlorophyll content was analyzed. For each type of leaf greenness, the relative SPAD value was recorded (five points/leaf) and the same leaves sampled for chlorophyll content determination. Leaf disk $3 \mathrm{~mm}$ in diameter was obtained from leaf sample using a hole puncher. For each seedling the measurement was conducted on the youngest fully expanded leaves on each plant, generally the second or third leaf from the tip of the stem was used. The leaf disks were immediately immersed in acetone $(20 \mathrm{~mL})$ in an aluminum foil-covered glass bottle for approximately 24 hours at $0{ }^{\circ} \mathrm{C}$ until all the green colour had bleached out. Finally, the solution $(3.5 \mathrm{~mL})$ was transferred to measure at absorbances of 664 and $647 \mathrm{~nm}$ using a spectrometer (UV-3101P, Labomed Inc, USA). After that the least squares regression was used to develop predictive relation between SPAD meter readings and pigment concentrations $(\mathrm{mg} / \mathrm{g}$ fresh weight) obtained from the chlorophyll destructive analysis.

\subsection{Total Carbon, Nitrogen and C:N Ratio}

Total carbon and C:N ratio were measured by using a CNS 2000 analyzer (Model A Analyst 300, LECO Inc, USA). This was performed by placing ground leaf sample $(0.05 \mathrm{~g})$ into the combustion boat. Successively, the combustion boat was transferred to the loader before the sample was burned at $1,350{ }^{\circ} \mathrm{C}$ to obtain the reading of total carbon and nitrogen content of the samples.

\subsection{Photosynthesis and Photosynthesis Nitrogen Use Efficiency (PNUE)}

The measurement was obtained from a closed infra-red gas analyzer LICOR 6400 Portable Photosynthesis System system (IRGA, Licor Inc. Nebraska, USA). Prior to use, the instrument was warmed for 30 minutes and calibrated with the ZERO IRGA mode. Two steps are required in the calibration process: first, the initial zeroing process for the built-in flow meter; and second, zeroing process for the infra-red gas analyzer. The measurements used optimal conditions set by Jaafar et al. [38] of $400 \mu \mathrm{mol} / \mathrm{mol} \mathrm{CO}_{2} 30{ }^{\circ} \mathrm{C}$ cuvette temperature, $60 \%$ relative humidity with air flow rate set at $500 \mathrm{~cm}^{3} / \mathrm{min}$, and modified cuvette condition of $800 \mu \mathrm{mol} \mathrm{m} \mathrm{m}^{-2} \mathrm{~s}^{-1}$ photosynthetically photon flux density (PPFD). The measurements of gas exchange were carried out between 09:00 to 11:00 a.m. using fully expanded young leaves numbered three and four from plant apex to record net 
photosynthesis rate (A). The operation was automatic and the data were stored in the LI-6400 console and analyzed by "Photosyn Assistant" software (Version 3, Lincoln Inc, USA) [38] Several precautions were taken to avoid errors during measurements. Leaf surfaces were cleaned and dried using tissue paper before enclosed in the leaf cuvette. Photosynthesis nitrogen use efficiency (PNUE) was calculated by dividing the photosynthesis to nitrogen content of leaves [39].

\subsection{Statistical Analysis}

Data were analyzed using analysis of variance by SAS version 17. Mean separation test between treatments was performed using Duncan multiple range test and standard error of differences between means was calculated with the assumption that data were normally distributed and equally replicated.

\section{Conclusions}

This study demonstrated that enrichment with high levels of $\mathrm{CO}_{2}$ can enhance the production of plant secondary metabolites, in particular the total phenolics and total flavonoids, in plant. However, increased nitrogen fertilization can reduce the production of these plant secondary metabolites under $\mathrm{CO}_{2}$ enrichment. When there were accumulation of TNC in plant leaves and reduction in photosynthesis, the production of plant secondary metabolites might be up-regulated. The increase in the production of plant secondary metabolites was indicated by increases in the values of $\mathrm{C}: \mathrm{N}$ ratio, PNUE and reduction in chlorophyll contents.

\section{Acknowledgements}

The authors are grateful to the Ministry of Higher Education Malaysia for financing this work under the Research University Grant Scheme No. 91007.

\section{References and Notes}

1. Jaafar, H.Z.E.; Mohamed, H.N.B.; Rahmat, A. Accumulation and partitioning of total phenols in two varieties of Labisia pumila Benth. under manipulation of greenhouse irradiance. Acta Hort. 2008, 797, 387-392.

2. Burkill, I.H. A Dictionary of the Economic Products of the Malay Peninsula, 2nd ed.; Government of Malaysia and Singapore Publication: Kuala Lumpur, Malaysia, 1935.

3. Stone, B.C. Notes on the genus Labisia Lindyl (Myrsinaceae). Malayan Nat. J. 1988, 42, 43-51.

4. Rozihawati, Z.; Aminah, H.; Lokman, N. Preliminary trials on the rooting ability of Labisia pumila cuttings. In Malaysia Science and Technology Congress 2003; Agricultural Sciences: Kuala Lumpur, Malaysia, 2003.

5. Jamia, A.J.; Ibrahim, J.; Khairana, H.; Juriyati, H. Perkembangan Penyelidikan dan Pembangunan Kacip Fatimah; New Dimension in Complementary Health Care: Kuala Lumpur, Malaysia, 2004; pp. 13-19.

6. Namiki, M. Antioxidant/antimutagens in food, critical reviews of food science and nutrition. Food Sci. Nutr. 1990, 29, 273-300. 
7. Briskin, D.P.; Gawienowski, M.C. Differential effects of light and nitrogen on the production of hypericins and leaf glands in Hypericum perforatum. Plant Physiol. 2001, 39, 1075-1081.

8. Jaafar, H.Z.E.; Ibrahim, M.H.; Por, L.S. Effects of $\mathrm{CO}_{2}$ enrichment on accumulation of total phenols, flavonoid and chlorophyll content in two varieties of Labisia pumila Benth. exposed to different shade levels. In Proceedings of International Conference on Balanced Nutrient Management for Tropical Agriculture, Kuantan, Pahang, Malaysia, 15-22 February 2010; UPM: Kuala Lumpur, Malaysia, 2010; pp. 112-114.

9. Ali, G.; Hawa, Z.E.J.; Asmah, R. Elevated carbon dioxide increases contents of flavonoids and phenolics compound, and antioxidant activities in Malaysian Young Ginger (Zingiber officinale Roscoe) varieties. Molecules 2010, 15, 7907-7922.

10. Nothrup, R.R.; Dahlgren, R.A.; McColl, J.G. Polyphenols as regulators of plant-litter-soil interaction: a positive feedback. Biogeochemistry 1998, 42, 189-220.

11. Boudet, A.M.; Kajita, S.; Grima-Pattenati, J.; Goffner, D. Lignin and lignocellulosics: a better control of synthesis for new and improved uses. Trends Plant Sci. 2003, 8, 576-581.

12. Bryant, J.P.; Chapin, F.S.; Klein, D.R. Carbon nutrient balance of boreal plants in relation to vertebrate herbivory. Oikos 1983, 40, 357-368.

13. Reichardt, P.B.; Chapin, F.S.; Bryant, J.P.; Mattes, B.R.; Clausen, T.P. Carbon nutrient balance as a predictor of plant defense in Alaskan balsam poplar: a potential importance of metabolite turnover. Oecologica 1991, 88, 401-406.

14. Lindroth, R.L.; Osier, T.L.; Barnhill, H.R.H.; Wood, S.A. Effects of genotype and nutrient availability on photochemistry of trembling aspen (Populus tremoides Mich.) during leaf senescence. Biochem. Syst. Ecol. 2002, 30, 297-307.

15. Norby, R.J.; Iverson, C.M. Nitrogen uptake, distribution, turnover, and efficiency of use in a $\mathrm{CO}_{2}$ enriched sweetgum forest. Ecology 2006, 87, 5-14.

16. Koricheva, J.; Larsson, S.; Haukioja, E.; Keinanen, M. Regulation of woody plant secondary metabolism by resource availability: hypothesis means by meta-analysis. Oikos 1998, 83, 212-226.

17. Felgines, C.; Texier, O.; Morand, C.; Manach, C.; Scalbert, A.; Regerat, F.; Remesy, C. Bioavailability of the flavone naringenin and its glycosides in rats. Amer. J. Physiol. Gastrointest. Liver Physiol. 2000, 279, 1148-1154.

18. Amin, A.A.; Rashad, M.; El-Abagy, H.M.H. Physiological effects of indole-3-Butyric-Acid and Salicylic acid on growth, yield and chemical constituents of onion plants. J. Appl. Sci. Res. 2007, 3, 1554-1563.

19. Tissue, D.T.; Thomas, R.B.; Strain, B.R. Atmospheric $\mathrm{CO}_{2}$ increases growth and photosynthesis of Pinus taedea: a four year field experiment. Plant Cell Environ. 1997, 20, 1123-1134.

20. Den-Hertog, J.; Stulen, L.; Fonseca, E.; Delea, P. Modulation of carbon and nitrogen allocation in Urtica diocia and Plantago major by elevated $\mathrm{CO}_{2}$ : impact of accumulation of non-structural carbohydrates and ontogenic drift. Physiol. Planta 1996, 98, 77-88.

21. Poorter, H.; Berkel, V.; Baxter, R.; Den-Hertog, J.; Dijkstra, P.; Gifford, R.M.; Griffin, K.L.; Roumet, C.; Roy, J.; Wong, S.C. The effects of elevated $\mathrm{CO}_{2}$ on the chemical composition and construction costs of leaves of 27 C3 species. Plant Cell Environ. 1997, 20, 472-482. 
22. Baxter, R.; Ashenden, T.W.; Farrar, J. Effects of elevated $\mathrm{CO}_{2}$ and nutrient status on growth, dry matter partitioning and nutrient content of Poa alpinia var. vivpara L. J. Exp. Bot. 1997, 48, 1477-1486.

23. Fonseca, F.; Bowsher, C.; Stulen, I. Impact of elevated atmospheric CO2 and nitrate reductase transcription and activity in leaves and roots of Plantago major. Physiol. Planta 1997, 100, 940-948.

24. Reddy, A.R.; Reddy, K.R.; Padjung, R.; Hodges, H.F. Nitrogen nutrition and photosynthesis in leaves of pima cotton. J. Plant Nutr. 1996, 19, 755-790.

25. Tognetti, R.; Johnson, J.D. The effect of elevated atmospheric $\mathrm{CO}_{2}$ concentration and nutrient supply on gas exchange, carbohydrates and foliar phenolics concentration in live oak (Quercus virginiana Mill.) seedlings. Ann. For. Sci. 1999, 56, 379-389.

26. Jacob, J.; Gretiner, C.; Drake, B.G. Acclimation of photosynthesis in relation to rubisco and non structural carbohydrate contents and in situ carboxylase activity in Scirpus olnelyi grown at elevated $\mathrm{CO}_{2}$ in the field. Plant Cell Environ. 1995, 18, 875-884.

27. Fan, Y.; Wang, Y.; Tan, R.; Zhang, Z. Seasonal and sexual variety of ginko flavonol glycosides in leaves of Gingko biloba L. J. Trad. Chin. Med. 1998, 23, 267-269.

28. Geiger, M.; Walch-Piu, L.; Harnecker, J.; Schulze, E.D.; Stitt, M. Enhanced $\mathrm{CO}_{2}$ leads to a modified diurnal rhythm of nitrate reductase activity in older plants and a large stimulation of nitrate reductase activity and higher levels of amino acids in higher plants. Plant Cell Environ. 1998, 21, 253-268.

29. Winger, A.; Purdy, S.; Maclean, A.; Pourtau, N. The role of sugars in integrating environmental signals during the regulation of leaf senescence. New Phytol. 2006, 161, 781-789.

30. Lambers, $\mathrm{H}$. Rising $\mathrm{CO}_{2}$, secondary plant metabolism, plant-herbivore interactions and litter decomposition. Theoretical Considerations. Vegetatio 1993, 104-105, 263-271.

31. Suza, R.; Valio, I.F.M. Leaf optical properties as affected by shade in samplings of six tropical tree species differing in succesional status. Braz. J. Plant Physiol. 2003, 15, 49-54.

32. Meyer, S.; Cerovic, Z.G.; Goulas, Y.; Montpied, P., Demotes, S.; Bidel, L.P.R.; Moya, I.; Dreyer, E. Relationship between assessed polyphenols and chlorophyll contents and leaf mass per area ratio in woody plants. Plant Cell Environ. 2006, 29, 1338-1348.

33. Michel, H.; Klaus, K. The protective functions of caretenoids and flavonoid pigments against excess visible radiation at chilling temperature investigated in Arabidopsis. Planta 2001, 213, 953-966.

34. Jaafar, H.Z.E. Carbon dioxide enrichment technology for improved productivity under controlled environment system in the tropics. Acta Hort. 2006, 742, 353-363.

35. Thayumanam, B.; Sidasivam, S. Carbohydrate chemistry .Qual. Plant Foods Hum. Nutr. 1984, 34, 253-254.

36. Edward, J.N. The effects of trinexapac ethyl and three nitrogen sources on creeping bentgrass (Agrostis stolonnifera) grown under three light environments. Master Thesis, Faculty of Horticulture and Crop Science, The Ohio State University, 2008.

37. Idso, S.B.; Kimball, B.A.; Hendrix, D.L. Effects of atmospheric $\mathrm{CO}_{2}$ enrichment on chlorophyll and nitrogen nutrition concentrations of four sour orange tree leaves. Environ. Exp. Bot. 1996, 36, 323-331. 
38. Jaafar, Z.E.J.; Mohd Hafiz, I.; Philip E. Leaf gas exchange properties of three varieties of Labisia pumila Benth. under greenhouse conditions. J. Trop. Plant Physiol. 2009, 3, 16-24.

39. Ibrahim, M.H.; Jaafar, H.Z.E.; Haniff, M.; Yusop, R. Changes in the growth and photosynthetic patterns of oil palm (Elaeis guineensis Jacq.) seedlings exposed to short term $\mathrm{CO}_{2}$ enrichment in a Closed Top Chamber. Acta Physiol. Plant 2010, 32, 305-313.

40. Sanz-Saez, A.; Gorka, E.; Iker, A.; Salvador. N.; Irrogen, J.J.; Sanchez-Diaz, M. Photosynthetic downregulation under elevated $\mathrm{CO}_{2}$ exposure can be prevented by nitrogen supply in nodulated alfalfa. J. Plant Physiol. 2010, 167, 1558-1565.

Sample Availability: Samples of the compounds are available from the authors.

(C) 2010 by the authors; licensee MDPI, Basel, Switzerland. This article is an open access article distributed under the terms and conditions of the Creative Commons Attribution license (http://creativecommons.org/licenses/by/3.0/). 